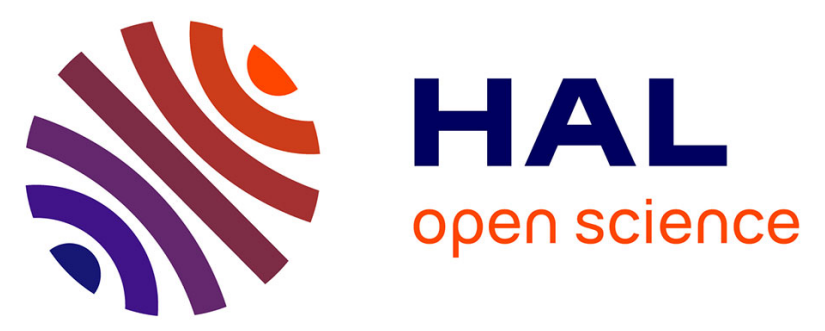

\title{
Novel triazole nucleoside analogues promote anticancer activity via both apoptosis and autophagy
}

Yanhua Zhang, Xi Liu, Yun Lin, Baoping Lian, Wenjun Lan, Juan L Iovanna, Xiaoxuan Liu, Ling Peng, Yi Xia

\section{- To cite this version:}

Yanhua Zhang, Xi Liu, Yun Lin, Baoping Lian, Wenjun Lan, et al.. Novel triazole nucleoside analogues promote anticancer activity via both apoptosis and autophagy. Chemical Communications, 2020, 56 (69), pp.10014-10017. 10.1039/d0cc04660d . hal-02992738

\section{HAL Id: hal-02992738 \\ https://hal.science/hal-02992738}

Submitted on 18 Nov 2020

HAL is a multi-disciplinary open access archive for the deposit and dissemination of scientific research documents, whether they are published or not. The documents may come from teaching and research institutions in France or abroad, or from public or private research centers.
L'archive ouverte pluridisciplinaire HAL, est destinée au dépôt et à la diffusion de documents scientifiques de niveau recherche, publiés ou non, émanant des établissements d'enseignement et de recherche français ou étrangers, des laboratoires publics ou privés. 


\section{Novel Triazole Nucleoside Analogues Promotes Anticancer Activity via Both Apoptosis and Autophagy ${ }^{\dagger}$}

Received 00th January 20xx, Accepted 00th January 20xx DOI: $10.1039 / \times 0 \times x 00000 x$

\author{
Yanhua Zhang, ${ }^{\text {a\# }}$ Xi Liu, ${ }^{\text {a\# }}$ Yun Lin, ${ }^{a}$ Baoping Lian, ${ }^{b}$ Wenjun Lan, ${ }^{\text {cd }}$ Juan L. Iovanna, ${ }^{d}$ Xiaoxuan Liu, ${ }^{\text {b* }}$ \\ Ling Peng ${ }^{\mathrm{c}}$ and $\mathrm{Yi} \mathrm{Xia}^{\mathrm{a} *}$
}

Novel nucleoside derivatives were developed using the strategy of "terminal N, N-dimethylation" to impart tertiary amines to a 1,2,4triazole nucleoside. The obtained lead compounds displayed significantly improved anticancer activity with dual mechanisms of cell death via apoptosis and autophagy, offering a fresh perspective to searching for new anticancer candidates.

Nucleoside drugs are synthetic mimics of natural nucleosides and are an important class of drugs. ${ }^{1}$ Because of their structural resemblance to natural nucleosides, nucleoside drugs exhibit various pharmacological activities via antimetabolite activity, by inhibiting nucleic acid synthesis and/or by interfering with biological events involving nucleosides or nucleotides. ${ }^{2,} 3$ The Food and Drug Administration (FDA) has approved more than 20 antiviral and anticancer nucleoside drugs, including ribavirin and acyclovir etc (Fig. 1). ${ }^{2,3}$ Currently, clinical trials are underway as an emergency to evaluate remdesivir, a prodrug of a nucleoside analogue, as a treatment for COVID-19, for which there's no effective treatment. ${ }^{4}$

The search for nucleoside analogues as drug candidates has long been an active area of research. Usually these nucleoside candidates carry either modified nucleobases or altered sugar moiety or a combination of both. It is worth noting that nucleoside analogues bearing unnatural nucleobases often have improved stability and biological activity with unique modes of action; ribavirin is considered a canonical example of this. Ribavirin is the first antiviral nucleoside drug to have a

\footnotetext{
${ }^{a}$ Chongqing Key Laboratory of Natural Product Synthesis and Drug Research School of Pharmaceutical Sciences, Chongqing University, China. E-mail: yixia@cqu.edu.cn

${ }^{b}$ State Key Laboratory of Natural Medicines and Jiangsu Key Laboratory of Drug Discovery for Metabolic Diseases, Center of Advanced Pharmaceuticals and Biomaterials, China Pharmaceutical University, Nanjing 210009, P. R. China. E-mail: xiaoxuanliu@cpu.edu.cn

Aix-Marseille Université, CNRS, Centre Interdisciplinaire de Nanoscience de Marseille (CINaM), UMR 7325, Equipe Labellisé par La Ligue, France.

${ }^{d}$ Centre de Recherche en Cancérologie de Marseille (CRCM), INSERM U1068, CNRS, Aix-Marseille Université and Institut Paoli-Calmettes, Marseille 13288, France.

${ }^{e} Y Z$ and $X L$ contribute equally to this work.

+ Electronic Supplementary Information (ESI) available: See DOI: $10.1039 / \times 0 \times x 00000$
}

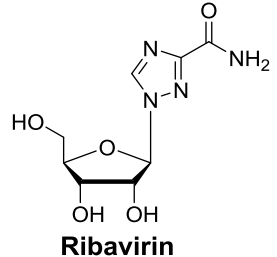<smiles>Nc1nc2c(ncn2COCO)c(=O)[nH]1</smiles><smiles>Cc1ccc(C#Cc2nc(C(N)=O)nn2COCO)cc1</smiles>

WMH-116

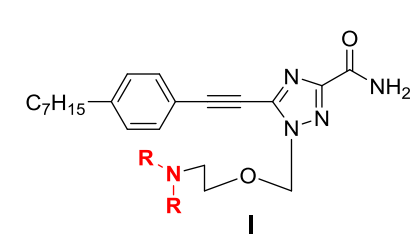

Fig. 1 Chemical structures of the nucleoside drugs ribavirin and acyclovir, the arylethynyltriazole nucleoside $\mathbf{W M H - 1 1 6}$, and the amine-containing triazole nucleoside derivatives I studied in this work.

1,2,4-triazole ring as the unnatural nucleobase, ${ }^{5}$ and has immunomodulatory activity in addition to its antimetabolite activity. ${ }^{6,7}$ In the quest to find novel triazole nucleoside derivatives with anticancer and antiviral properties, we have identified arylethynyltriazole nucleosides, which have interesting biological activity and novel mechanisms of action, such as inhibition of heat shock factor 1 (HSF1) and heat shock proteins (HSPs). ${ }^{8,9}$ Of these, WMH-116 is one of the most potent analogues (Fig. 1). However, aryltriazole nucleoside analogues often have poor water solubility and hence limited bioavailability, which severely impedes their further clinical translation. Efforts are therefore required to overcome the solubility limitations via further modifications to improve the physicochemical properties, as well as the biological activity, of nucleoside analogues.

Nitrogen-containing groups, such as amines or various nitrogen heterocycles, are frequently encountered structural motifs among pharmacologically active scaffolds in medicinal chemistry. In addition, $\mathrm{N}$-methylation is considered a precious tool to introduce conformational rigidity, lipophilicity, and ionization properties, impacting the bioavailability of active molecules. ${ }^{10,11}$ Moreover, $\mathrm{N}$-methylation can contribute to the strongly increased biological activity of amine compounds 
associated with so-called "terminal dimethylation". ${ }^{12,13}$ On the basis of these considerations, we wanted to introduce a methylated amine motif to $\mathbf{W M H - 1 1 6}$, with a view to improving its physicochemical properties and biological activity. Considering the structural features of parent compound, we reasoned that introducing a methylated amine motif to the hydroxyl group in the acyclic sugar chain was the most effective means of constructing amine-containing triazole nucleosides, herein termed I (Fig. 1). Indeed, all the synthesized compounds I had significantly enhanced anticancer activity. More importantly, this structural modification imparted a new mechanism of inducing cell death, namely, autophagy-induced cell death, which contributed favourably to the anticancer activity. Here, we report our results of this study.

We started the synthesis of the nucleoside analogue I with WMH-116, which was first transformed to the tolylsulfonyl analogue $\mathbf{I - 2}$. The subsequent conversion of $\mathbf{I - 2}$ to la using dimethylamine in refluxing $\mathrm{EtOH}^{14}$ (Table 1 ) was problematic and resulted in low yields (data not shown). This is because the product la was obtained in the form of toluenesulfonate salt, and its removal using $5 \% \mathrm{NaOH}$ and repeated extraction was not efficient, leading to significant product loss and hence low yield. To circumvent this problem, we transformed I-2 to the bromide I-1, which was then treated with various secondary amines including heterocycles to afford la-If in good to excellent yields (Table 1). It is to note that unlike $\mathbf{W M H - 1 1 6}$, the solubility of I was $\mathrm{pH}$ dependent. This is in line with the protonation feature of the tertiary amine functionality, which is largely in its protonated form at $\mathrm{pH}<7.0$, thereby improving solubility in water.

With the synthesized compounds la-If in hand, we next evaluated their anticancer activity in various cancer cells by assessing cell proliferation using an MTT assay. As shown in Table 1, all the derivatives la-If had superior antiproliferative activity compared to $\mathbf{W M H - 1 1 6}$ and to the reference triazole nucleoside drug ribavirin. Among them, la and $\mathbf{l b}$, two compounds that had dimethylamino and diethylamino terminals, respectively, showed similar activity in most tested cancer cells. The compounds modified by the $\mathrm{N}$-heterocyclic substitutes pyrrolidine, piperidine, and piperazine (Ic-le) exhibited further improved antiproliferative activity in Panc-1 and SKOV3 cells compared to $\mathbf{l a}$ and $\mathbf{~} \mathbf{l b}$. It is noteworthy that compound If, which had an additional alkyl tertiary amine incorporated into the piperazine ring, elicited the most potent activity. Interestingly, this finding corroborates those obtained from our previous studies that a trifluoperazine analogue having additional piperazine and alkyl tertiary amine had a dramatic increase in anticancer activity. ${ }^{15}$ Together, this study alongside our previous work $^{15}$ support the strategy of "terminal $N, N$-dimethylation" for lead optimization.

Since WMH-116 exercises its anticancer activity via targeting the heat shock response pathway ${ }^{9}$, we therefore asked whether the compounds la-If, analogues of $\mathbf{W M H - 1 1 6}$, also maintained a similar mode of action. We selected two representative compounds, la and If, which bear simple dimethylamino and $\mathrm{N}$-heterocyclic amino functionalities,
Table 1 Synthesis of triazole nucleosides $\mathbf{I}$ and their antiproliferative activity on cancer cells.

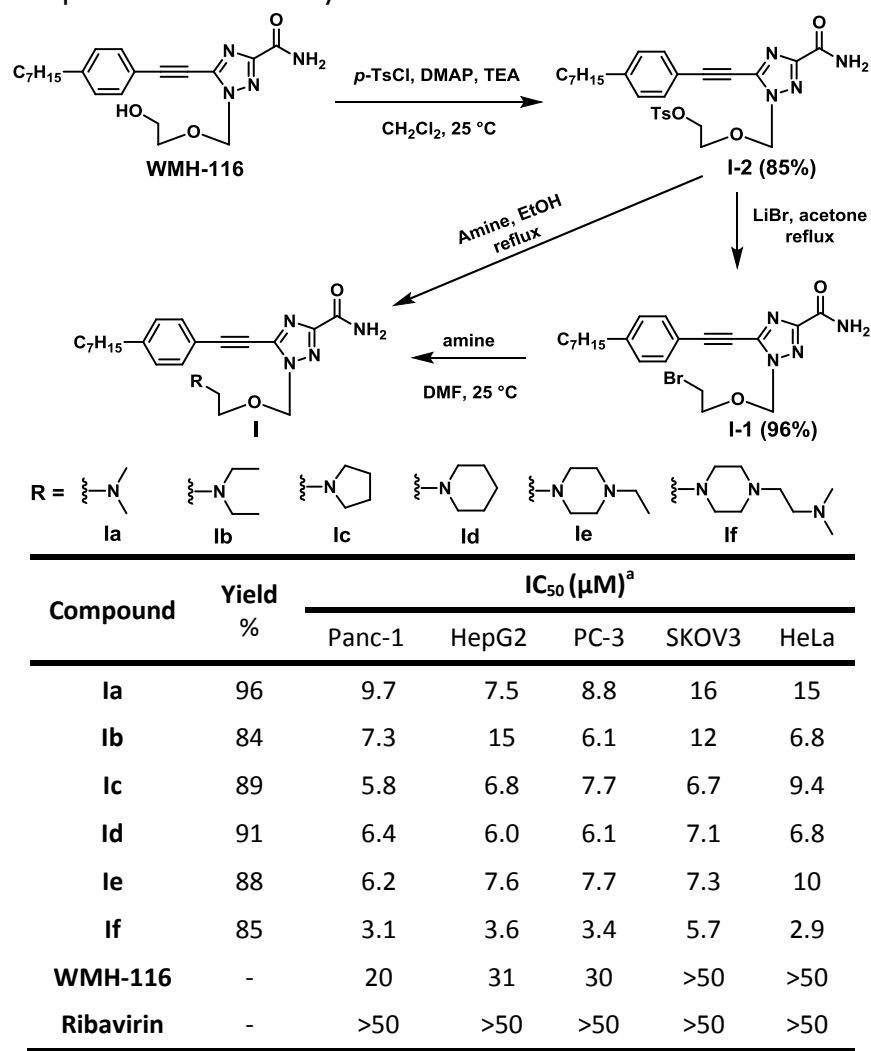

${ }_{1} \mathrm{C}_{50}$ represents the concentration of a compound that is required for $50 \%$ inhibition of cell growth.

respectively, to examine their effects on HSF1, the primary transcription factor of stress-inducible HSPs. ${ }^{16}$ As shown in Figure 2, the expression of HSF1 at a protein level was attenuated in a dose-dependent manner upon treatment with both compounds, with almost complete attenuation at higher concentrations. This was also the case for HSP27 and HSP9O $\alpha$, two stress-inducible proteins that are controlled by HSF1 and that also play key roles in the heat shock response pathway, in particular by promoting cancer cell proliferation and drug resistance. ${ }^{17}$ It should be noted that HSPs function as

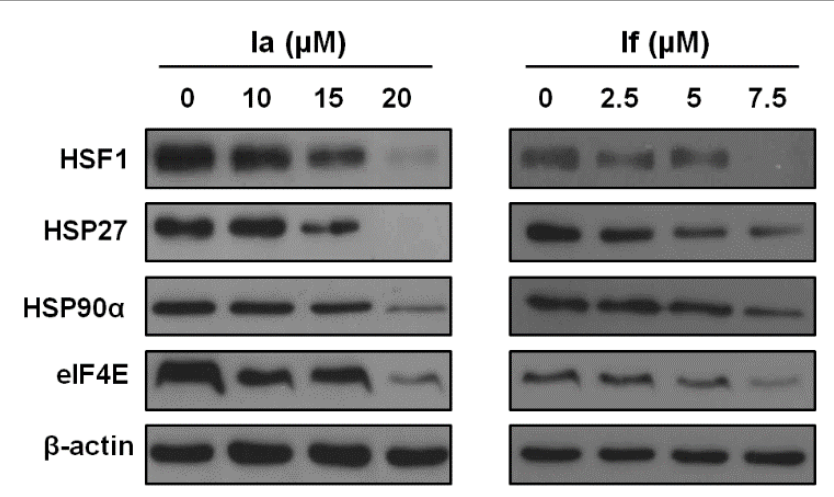

Fig. 2 Compounds la and If downregulated proteins involved in the heat shock response pathway. la and If strongly inhibited the expression of HSF1, the downstream heat shock proteins HSP27 and HSP9O $\alpha$, and their client oncoprotein elF4E in pancreatic cancer Panc-1 cells in a dose-dependent manner. 
molecular chaperones to stabilize their client proteins, and so inhibition of HSPs will result in the degradation of their client proteins. We therefore also assessed eukaryotic translation initiation factor 4E (elF4E), the client protein of HSP27.18 As Figure 2 illustrates, both la and If effectively reduced the expression of elF4E. Therefore, like WMH-116, la and If were able to suppress the expression of HSPs and their client protein, which contributed to their anticancer activity.

Both HSF1 and its downstream HSPs act in diverse cellular processes and molecular mechanisms, including apoptosis, the physiologically important method of programmed cell death. ${ }^{19}$ To investigate whether this new family of triazole nucleosides could promote cancer cells toward apoptosis, we treated pancreatic cancer Panc-1 cells with the most potent lead If; staining with annexin V-FITC and propidium iodide (PI) followed by cytometric analysis determined the percentage of apoptotic cells. The increase in apoptotic cells highlighted that If suppressed cell growth via apoptosis (Fig. 3A). Its ability to induce apoptosis was further assessed by detecting the expression of biomarkers involved in apoptosis, such as the cleavage products of PARP (poly ADP-ribose polymerase) and $B C L-2$. PARP is a family of proteins involved in different cellular processes and its cleavage serves as a marker of cells undergoing apoptosis, ${ }^{20}$ while $\mathrm{BCL}-2$ plays a crucial role in regulating cell death by inhibiting apoptosis. ${ }^{21}$ Indeed, If increased the level of cleaved PARP, and at the same time, suppressed BCL-2 expression (Fig. 3B), confirming the ability of If to promote apoptosis.

We were also curious whether If initiated other pathways besides apoptosis to cause cell death. Autophagy is an evolutionarily conserved catabolic process in which cellular materials are delivered to lysosomes for degradation. Furthermore, autophagy not only plays a crucial role in cell survival but also acts as a specific mechanism of cell death. ${ }^{22}$ Several studies have revealed a relationship between HSPs and autophagy. For example, HSP9O increases chemoresistance via regulating autophagy, and autophagy also influences HSP9Omediated antiapoptotic effects. ${ }^{23}$ Moreover, several nucleoside analogues could cause autophagy-induced cell death; for example, the 1,2,3-triazolyl nucleoside derivatives developed by Benhida et al. suppressed tumor cell growth via both apoptosis and autophagy. ${ }^{24,25}$ We therefore investigated whether If could induce cell death via autophagy. As the microtubule-associated protein-1 light chain 3B (LC3B) is required for formation of autophagosomes, ${ }^{26}$ an increase in

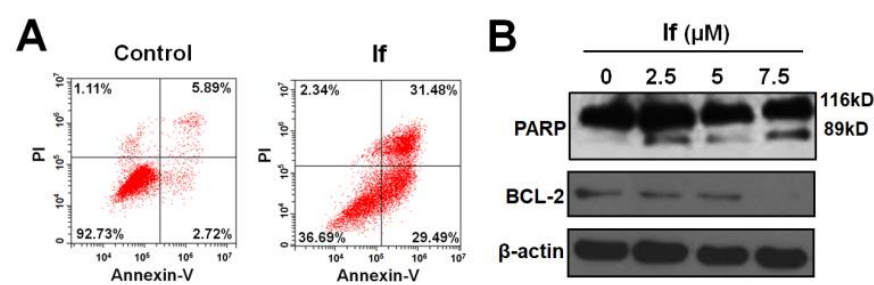

Fig. 3 Compounds If induced apoptosis in pancreatic cancer Panc-1 cells. (A) Flow cytometry quantified cells undergoing apoptosis (annexin V-positive cells) and necrosis (PI-positive cells). Untreated Panc- 1 cells were used as the reference control. (B) If efficiently led to the cleavage of PARP and downregulation of BCL-2.
LC3B lipidation and cleavage are considered hallmarks of autophagy induction. We then verified the expression of LC3B in Panc-1 cells using western blotting and immunofluorescent assays. As shown in Figure 4A, If caused a remarkable increase in autophagic activity, which is drastically different from WMH-116. In addition, immunofluorescent staining of LC3B was performed to visually detect cellular changes during autophagic activity. Incubation of If with Panc-1 cells led to a considerable increase in autophagic punctate dots (Fig. 4B), indicating autophagosome formation. To further examine whether If induced autophagy or behaved as autophagy inhibitors like cholorquine, we combined If with chloroquine to treat Panc- 1 cells. Figure $4 \mathrm{C}$ demonstrated that co-treatment with chloroquine and If increased considerably the conversion to LC3B-I to LC3B-II, suggesting that If effectively induced autophagy.

As autophagy may exhibit opposing, context-dependent roles in cancer, it was important to determine whether the autophagy induced by If plays a pro-survival role or activates the death cascade. Interestingly, when autophagy was inhibited by chloroquine, the proliferation of cells treated by If recovered (Fig. 4D), suggesting that the antiproliferative activity of If can be partially ascribed to its ability to induce autophagic cell death in addition to apoptosis.

After confirming the anticancer activity and mode of action in vitro, we next assessed the antitumor effects of If in nude mice bearing Panc-1-xenografted tumors (Fig. 5). Mice with mean tumor volumes of $100 \mathrm{~mm}^{3}$ were randomly selected for treatment with If versus treatment with PBS buffer as control. Upon intraperitoneal (ip) injections for 4 consecutive weeks, If significantly reduced the Panc-1 tumor volume by $70 \%$ compared to the PBS group (Fig. 5A). In addition, cancer cell proliferation was considerably reduced in tumor tissues, as

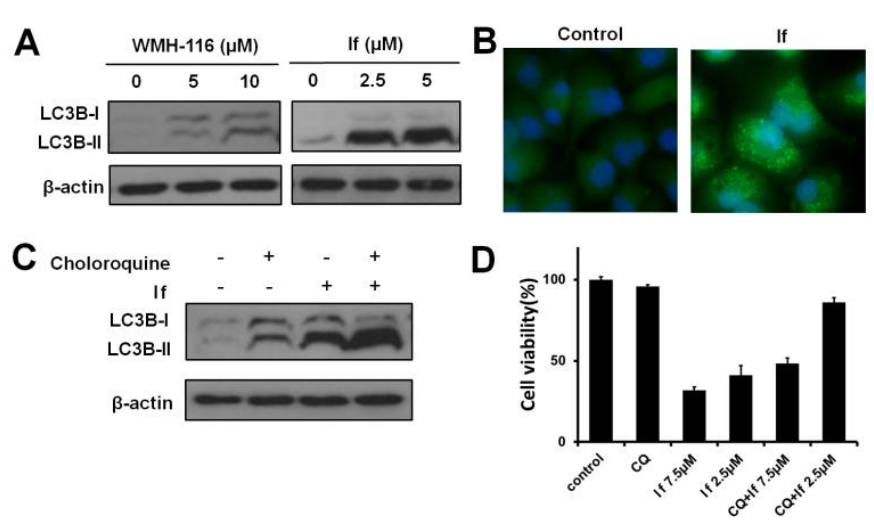

Fig. 4 Compound If activated autophagy-induced cell death in pancreatic cancer Panc-1 cells. (A) Western blotting analysis of LC3B-I conversion to LC3B-II in Panc-1 cells. Panc-1 cells were treated with various concentrations of WMH-116 and If, following which whole-cell lysates were analyzed for LC3B expression, with $\beta$-actin as the reference. (B) Immunofluorescence analysis of LC3B localization in Panc-1 cells treated with If, showing the appearance of a punctate staining pattern. Bright green spots: LC3B; blue: Hoechst 33342 . (C) Panc-1 cells were treated with If with or without the autophagy inhibitor chloroquine to determine levels of autophagic flux. (D) The proliferation of Panc-1 cells recovered following the co-treatment with chloroquine (CQ) and If, indicating that If may exhibit antiproliferative activity via induction of autophagy. 
A

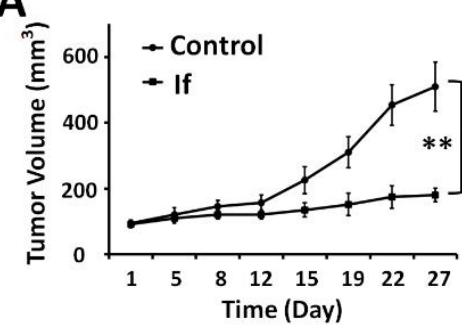

B

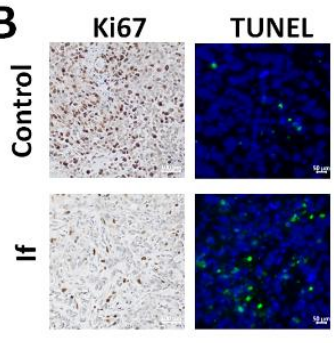

Fig. 5 Effect of If treatment on Panc-1 tumor growth in vivo. (A) If inhibited tumor growth. If was injected intraperitoneally $(20 \mathrm{mg} / \mathrm{kg})$ for 4 weeks. The tumor volumes were measured twice a week. ${ }^{* *} p<0.01$ vs control (Student's $t$ test). All results are expressed as the mean \pm S.E $(n=5)$. Data points are the means of analysis; bars indicate standard errors. (B) In vivo tumor cell proliferation was measured by immunohistochemistry staining for Ki67; tumor cell apoptosis was detected by the TUNEL assay.

revealed by immunohistochemical analysis of $\mathrm{Ki}-67$, a cell proliferation marker. Also, much fewer Ki-67-positive cells were detected in the If-treated group compared to the PBStreated group, highlighting the effective antitumor activity of If (Fig. 5B). Meanwhile, TUNEL-positive cells were significantly increased in tumor tissues from If-treated mice, indicating the induction of apoptosis by If in vivo. Finally, no adverse effects occurred in the treated group indicating by their constant body weight and normal behaviour (Fig. S1A). Moreover, pathological examination of the major organs of the mice treated with If using $\mathrm{H} \& \mathrm{E}$ staining did not reveal any notable histopathological changes (Fig. S1B), further confirming that If did not cause any acute toxicity in the mouse model.

In summary, we have developed novel triazole nucleoside analogues la-If bearing amine functionalities at the sugar scaffold. Compared to their parent compound WMH-116, the various tertiary amine functionalities greatly improved their anticancer activity, with If being the most potent lead compound. Remarkably, If was able to induce autophagic cell death in addition to inducing apoptosis and inhibiting heat shock response pathways. Therefore, they constitute promising lead compounds with anticancer activity via dual mechanisms of inducing cell death. Importantly, the concept and strategy of introducing tertiary amine functionalities provide a new perspective in the search for novel and potent anticancer candidates to advance our drug discovery program.

This work is supported by the National Natural Science Foundation of China (81502920, 51773227); Graduate Research and Innovation Foundation of Chongqing, China (CYB19066); CAI YUANPEI Scholarship (201906050187); Jeunes Talents France-Chine Program (JTFC); Key Program for International S\&T Cooperation Projects of China (2018YFE0117800), the Youth Thousand-Talents Program of China.

\section{Conflicts of interest}

There are no conflicts of interest to declare.

\section{Notes and references}

1 L. P. Jordheim, D. Durantel, F. Zoulim and C. Dumontet, Nat. Rev. Drug Discov., 2013, 12, 447.

2 J. Shelton, X. Lu, J. A. Hollenbaugh, J. H. Cho, F. Amblard and R. F. Schinazi, Chem. Rev., 2016, 116, 14379.

3 E. De Clercq and G. Li, Clin. Microbiol. Rev., 2016, 29, 695.

4 F.-S. Wang and C. Zhang, Lancet, 2020, 395, 391.

5 S. Crotty, D. Maag, J. J. Arnold, W. Zhong, J. Y. N. Lau, Z. Hong, R. Andino and C. E. Cameron, Nat. Med., 2000, 6, 1375.

6 M. Zajac, I. Muszalska, A. Sobczak, A. Dadej, S. Tomczak and A. Jelinska, Eur. J. Med. Chem., 2019, 165, 225

7 J. Casaos, N. L. Gorelick, S. Huq, J. Choi, Y. Xia, R. Serra, R. Felder, T. Lott, R. E. Kast, I. Suk, H. Brem, B. Tyler and N. Skuli, Mol. Cancer Ther., 2019, 18, 1185.

8 Y. Xia, Y. Liu, P. Rocchi, M. Wang, Y. Fan, F. Qu, J. L. Iovanna and L. Peng, Cancer Lett., 2012, 318, 145.

9 Y. Xia, M. Wang, E. Beraldi, M. Cong, A. Zoubeidi, M. Gleave and L. Peng, Anticancer Agents Med. Chem., 2015, 15, 1333.

10 T. J. Poel, R. C. Thomas, W. J. Adams, P. A. Aristoff, M. R Barbachyn, F. E. Boyer, J. Brieland, R. Brideau, J. Brodfuehrer, A. P. Brown, A. L. Choy, M. Dermyer, M. Dority, C. W. Ford, R. C. Gadwood, D. Hanna, C. Hongliang, M. D. Huband, C. Huber, R. Kelly, J. Y. Kim, J. P. Martin, Jr., P. J. Pagano, D. Ross, L. Skerlos, M. C. Sulavik, T. Zhu, G. E. Zurenko and J. V. N. Vara Prasad, J. Med. Chem., 2007, 50, 5886.

11 E. J. Barreiro, A. E. Kummerle and C. A. M. Fraga, Chem. Rev. 2011, 111, 5215

12 C. J. Marasco, Jr., D. L. Kramer, J. Miller, C. W. Porter, C. J. Bacchi, D. Rattendi, L. Kucera, N. Iyer, R. Bernacki, P. Pera and J. R. Sufrin, J. Med. Chem., 2002, 45, 5112.

13 C. R. Kowol, W. Miklos, S. Pfaff, S. Hager, S. Kallus, K. Pelivan, M. Kubanik, E. A. Enyedy, W. Berger, P. Heffeter and B. K. Keppler, J. Med. Chem., 2016, 59, 6739.

14 M. A. Labroli, M. P. Dwyer, R. Shen, J. Popovici-Muller, Q. Pu J. Richard, K. Rosner, K. Paruch and T. J. Guzi, Tetrahedron Lett., 2014, 55, 598.

15 P. Santofimia-Castano, Y. Xia, W. Lan, Z. Zhou, C. Huang, L. Peng, P. Soubeyran, A. Velazquez-Campoy, O. Abian, B. Rizzuti, J. L. Neira and J. Iovanna, J. Clin. Invest., 2019, 129 2500.

16 R. Gomez-Pastor, E. T. Burchfiel and D. J. Thiele, Nat. Rev. Mol. Cell Biol. , 2018, 19, 4.

17 J. Wu, T. Liu, Z. Rios, Q. Mei, X. Lin and S. Cao, Trends Pharmacol. Sci., 2017, 38, 226.

18 C. Andrieu, D. Taieb, V. Baylot, S. Ettinger, P. Soubeyran, A De-Thonel, C. Nelson, C. Garrido, A. So, L. Fazli, F. Bladou, M. Gleave, J. L. Iovanna and P. Rocchi, Oncogene, 2010, 29 1883.

19 Z. Su, Z. Yang, Y. Xu, Y. Chen and Q. Yu, Mol. Cancer, 2015, 14,48

20 F. J. Oliver, G. de la Rubia, V. Rolli, M. C. Ruiz-Ruiz, G. de Murcia and J. M. Murcia, J. Biol. Chem., 1998, 273, 33533.

21 A. R. D. Delbridge, S. Grabow, A. Strasser and D. L. Vaux, Nat. Rev. Cancer, 2016, 16, 99.

22 D. Denton and S. Kumar, Cell Death Differ., 2019, 26, 605.

23 X. Xiao, W. Wang, Y. Li, D. Yang, X. Li, C. Shen, Y. Liu, X. Ke, S Guo and Z. Guo, J. Exp. Clin. Cancer Res., 2018, 37, 201.

24 H. Amdouni, G. Robert, M. Driowya, N. Furstoss, C. Metier, A. Dubois, M. Dufies, M. Zerhouni, F. Orange, S. Lacas-Gervais, K. Bougrin, A. R. Martin, P. Auberger and R. Benhida, J. Med. Chem., 2017, 60, 1523.

25 S. Alaoui, M. Dufies, M. Driowya, L. Demange, K. Bougrin, G. Robert, P. Auberger, G. Pages and R. Benhida, Bioorg. Med. Chem. Lett., 2017, 27, 1989.

26 J. M. M. Levy, C. G. Towers and A. Thorburn, Nat. Rev. Cancer, 2017, 17, 528 